\title{
CORRELAÇÕES ENTRE O TESTE HIPOSMÓTICO E A AVALIAÇÃO CLÁSSICA DO SÊMEN DE CAPRINOS
}

\author{
IsABelle Rayanne Sousa de Oliveira ${ }^{1}$, Heron Medeiros Alves ${ }^{1}$, Thibério Souza Castelo ${ }^{2}$, \\ FrANCISCO SILVESTRE BRILHANTE BEZERRA ${ }^{3}$, ANA CARLA DióGENES SUASSUNA BEZERRA ${ }^{2}$, \\ ALEXANDRE RODRIGUES SILVA ${ }^{4}$
}

\author{
${ }^{1}$ Pós-graduandos do Instituto Brasileiro de Veterinária, Jaguariúna, SP, Brasil \\ ${ }^{2}$ Pós-graduandos da Universidade Federal do Rio Grande do Norte, Mossoró, RN, Brasil \\ ${ }^{3}$ Professor Mestre da Universidade Federal do Rio Grande do Norte, Mossoró, RN, Brasil \\ ${ }^{4}$ Professor Doutor da Universidade Federal do Rio Grande do Norte, Mossoró, RN, Brasil - \\ legio2000@yahoo.com
}

\begin{abstract}
Avaliou-se a correlação entre a avaliação da integridade funcional de membrana espermática por meio do teste hiposmótico, utilizando-se soluções com diferentes osmolaridades, e as avaliações convencionais do sêmen fresco de caprinos. Foram utilizados 24 ejaculados de três caprinos machos, obtidos por vagina artificial, os quais foram imediatamente submetidos à avaliação clássica. Em seguida, as amostras foram divididas em cinco alíquotas e submetidas ao teste hiposmótico, utilizando-se água destilada $(0 \mathrm{mOsm} / \mathrm{L})$ e soluções de citrato de sódio e frutose de diferentes osmolaridades $(50 ; 100 ; 150$ e 200 $\mathrm{mOsm} / \mathrm{L}$ ). A solução de $100 \mathrm{mOsm} / \mathrm{L}$ obteve a maior
\end{abstract}

média de espermatozoides reagidos $(34,8 \%)$ ao teste hiposmótico ( $\mathrm{P}<0,05)$; por outro lado, a água destilada foi a que apresentou os menores valores $(20,8 \%)$. Não foram detectadas correlações significativas entre os espermatozoides reagidos ao teste hiposmótico e as demais características seminais $(\mathrm{P}>0,05)$. Apesar disso, recomenda-se que o teste hiposmótico seja realizado utilizando-se uma solução a base de citrato de sódio e frutose apresentando $100 \mathrm{mOsm} / \mathrm{L}$ para a avaliação da integridade funcional da membrana espermática na espécie caprina.

PALAVRAS-CHAVE: caprino; espermatozoide; teste hiposmótico.

\section{CORRELATIONS BETWEEN HYPOOSMOTIC SWELLING TEST AND THE CLASSICAL EVALUATION OF GOAT SEMEN}

\section{ABSTRACT}

We evaluated the correlation between the assessment of the functional integrity of the sperm membrane by hypoosmotic swelling tes,t using solutions with different osmolarities, and the conventional assessments of fresh semen in goats. A total of 24 ejaculates from three goats was obtained by artificial vagina and immediately submitted to the classical evaluation. Samples were divided into five aliquots and subjected to hypoosmotic test using distilled water $(0 \mathrm{mOsm} / \mathrm{L})$, and sodium citrate and fructose solutions at different osmolarities $(50 ; 100$;
150 and $200 \mathrm{mOsm} / \mathrm{L}$ ). The $100 \mathrm{mOsm} / \mathrm{L}$ solution showed the highest percentage of reacted sperm (34.8\%), but distilled water was the one with the lowest values $(20.8 \%)$. No significant correlations were detected between the reacted sperm verified by the hypoosmotic swelling test and other semen characteristics $(\mathrm{P}>0.05)$. Nevertheless, we recommend the carry out of the hypoosmotic test by using a $100 \mathrm{mOsm} / \mathrm{L}$ sodium citrate and fructose solution to assess the functional integrity of the sperm membrane in caprine species.

KEYWORDS: caprine; hyposmotic swelling test; sperm. 


\section{INTRODUÇÃO}

Os testes utilizados na rotina de análise do sêmen consistem, basicamente, na avaliação da concentração, morfologia e motilidade espermáticas, recomendados pelo Colégio Brasileiro de Reprodução Animal (CBRA, 1998). Contudo, há evidências de que tais parâmetros, isoladamente, não são suficientes para estimar o potencial de fertilidade de um ejaculado. Sabendose que a membrana plasmática está envolvida em trocas metabólicas com o meio, o estudo de sua funcionalidade torna-se essencial, haja vista a grande influência de sua atividade bioquímica nos processos de capacitação espermática e fertilização. E, quando realizado junto aos parâmetros tradicionais de avaliação do sêmen, resulta em determinação mais precisa dos índices de fertilidade (LEBOUEF et al., 2006).

JEYENDRAN et al. (1984) propuseram o uso do teste hiposmótico (HOST), por ser considerado um método simples e acessível, capaz de detectar alterações intensas na funcionalidade espermática em amostras que não seriam descartadas se somente os resultados de motilidade e morfologia espermáticas fossem considerados. Este teste se caracteriza pelo influxo de fluidos para o interior da célula espermática, sob condições hiposmóticas, até que o equilíbrio entre os compartimentos seja alcançado, sendo um indicativo de que o transporte de água através da membrana está ocorrendo normalmente (INAMASSU et al., 1999).

Apesar da relativa simplicidade do HOST, vários pontos podem ser trabalhados para torná-lo um teste de alta confiabilidade. Pode-se discutir desde qual soluto utilizar e a osmolaridade ideal da solução, até o número de células a serem contadas (MELO \& HENRY, 1999). Em estudos com sêmen de cães (BUENO et al., 2001), equinos (MELO \& HENRY, 1999), bovinos (SIQUEIRA et al., 2006) e bubalinos (LODHI et al., 2008), verificou-se a existência de correlação entre o HOST e outros parâmetros seminais, demonstrando que esse teste poderia ser utilizado como um teste preditivo de fertilidade. FONSECA et al. (2005) testaram soluções de 50 a $300 \mathrm{mOsm} / \mathrm{L}$ na tentativa de identificar a mais adequada a ser utilizada na avaliação do sêmen caprino fresco. No entanto, os autores avaliaram a integridade de membrana isoladamente e não estabeleceram correlação entre os resultados encontrados com outros parâmetros de qualidade espermática.

Dessa forma, este estudo se propõe a avaliar a correlação entre os resultados da integridade de membrana, encontrados por meio do HOST, utilizando-se soluções com diferentes osmolaridades, e os testes de avaliações convencionais do sêmen fresco de caprinos.

\section{MATERIAL E MÉTODOS}

$\mathrm{O}$ experimento foi conduzido em uma propriedade localizada no município de Mossoró, no Rio Grande do Norte, situado às coordenadas geográficas $5^{\circ} 11^{\prime}$ de Latitude Sul e $37^{\circ}$ de Longitude Oeste, com altitude média de $16 \mathrm{~m}$. O processamento do sêmen foi realizado no Laboratório de Conservação de Germoplasma Animal da Universidade Federal Rural do Semiárido (UFERSA).

Foram selecionados, para utilização no experimento, três caprinos machos adultos $(\sim 2$ anos de idade), submetidos à avaliação clínica completa e avaliação andrológica. Os animais eram mantidos em pastejo, tendo como suporte forrageiro principal a vegetação nativa tipo caatinga, com livre acesso à água e suplementação mineral. Dois dias antes da coleta de sêmen, os machos eram separados das fêmeas e mantidos em um piquete coberto com telhas de cerâmica. Todo o experimento foi realizado durante a estação seca na região.

Vinte e quatro ejaculados colhidos dos três caprinos (oito ejaculados por animal) por meio de vagina artificial e com auxílio de uma fêmea estrogenizada como manequim foram utilizados neste estudo. O sêmen foi colhido em tubos graduados e imediatamente encaminhado para avaliação, conforme as normas do CBRA (CBRA, 1998). A cor, o aspecto e o volume foram verificados no sêmen fresco. Critérios microscópicos como motilidade massal $(0-5)$ e motilidade progressiva (\%) foram avaliados subjetivamente usando-se microscopia de luz, com aumento de 100x. A porcentagem de espermatozoides viáveis foi avaliada por meio de um esfregaço de sêmen corado com Azul de Bromofenol, em que foram contadas 200 células em um aumento de 400x (DERIVAUX, 1980). A porcentagem de espermatozóides morfologicamente normais foi determinada por meio da contagem de 200 células em um esfregaço de sêmen corado com Rosa de Bengala, em microscopia óptica, com aumento de 1000x. Neste mesmo esfregaço, foi também determinada a integridade acrossomal das células espermáticas, estabelecendo-se a proporção de espermatozóides com acrossoma íntegro e não íntegro. 
Visando avaliar a integridade funcional da membrana plasmática, realizou-se o HOST. Para tanto, uma solução à base de citrato de sódio (50\%) e frutose (50\%) a $200 \mathrm{mOsm} / \mathrm{L}$ foi feita, de acordo com o método de REVELL \& MRODE (1994). Como proposto por CORREA \& ZAVOS (1994), diluições seriadas foram realizadas em água destilada formando soluções de quatro osmolaridades diferentes: 50; 100; 150 e $200 \mathrm{mOsm} / \mathrm{L}$.

As amostras de sêmen foram divididas em cinco alíquotas de $10 \mu \mathrm{L}$, sendo uma adicionada ao tubo contendo $1 \mathrm{~mL}$ de água destilada $(0 \mathrm{mOsm} / \mathrm{L})$ e as outras adicionadas aos tubos contendo $1 \mathrm{~mL}$ de solução a base de citrato de sódio e frutose (50; $100 ; 150$ e $200 \mathrm{mOsm} / \mathrm{L})$. Os tubos foram incubados em banho-maria e, após 40 minutos de incubação a $37^{\circ} \mathrm{C}$, uma alíquota de sêmen de cada tubo foi avaliada sob microscopia de contraste de fase $(400 x)$, sendo contadas 200 células. Os espermatozoides apresentando uma cauda dobrada e edemaciada foram considerados como portadores de uma membrana plasmática funcional (FONSECA et al., 2005). O resultado foi expresso em porcentagem, após a diferença entre a porcentagem de espermatozóides reativos ao HOST e porcentagem de espermatozóides que apresentaram patologias de cauda, durante o exame de morfologia espermática (MELO \& HENRY, 1999).
Para a análise estatística das características avaliadas, foi empregado o pacote estatístico Statistical Analysis System (SAS 6.10, SAS Institute Inc., Cary, NC, USA). A consistência dos dados e a análise descritiva (médias e desvio padrão) das características de interesse ao estudo foram realizadas mediante o emprego do PROC MEANS, a $5 \%$ de probabilidade $(\mathrm{P}<0,05)$. As variáveis estudadas foram submetidas ao teste de correlação de Pearson.

\section{RESULTADOS}

O sêmen fresco dos caprinos apresentou coloração amarelada, aspecto leitoso e o volume total dos ejaculados foi de $1,1 \pm 0,1 \mathrm{~mL}$. A motilidade massal foi de $3,85 \pm 0,16$ e a motilidade individual progressiva, $96,35 \pm 0,9 \%$. Um total de $94,05 \pm 1,26 \%$ de espermatozoides viáveis, 76,7 \pm $1,47 \%$ de espermatozóides com morfologia normal e $99,68 \pm 0,22 \%$ de espermatozóides com acrossoma intacto foi observado.

Com relação à integridade funcional da membrana, a solução apresentando $100 \mathrm{mOsm} / \mathrm{L}$ foi a que apresentou o maior percentual $(\mathrm{P}<0,05)$ de espermatozoides reativos ao teste hiposmótico (Tabela 1). Entretanto, nenhuma das soluções apresentou correlações significativas com 0 resultado de quaisquer das análises clássicas de sêmen (Tabela 2).

Tabela 1. Médias ( \pm desvio padrão) da porcentagem de espermatozoides caprinos reativos a soluções hiposmóticas de diferentes osmolaridades $(0 ; 50 ; 100 ; 150$ e $200 \mathrm{mOsm} / \mathrm{L} ; \mathrm{n}=24$ ejaculados $)$

\begin{tabular}{lccccc}
\hline & \multicolumn{5}{c}{ Osmolaridade das Soluções $(\mathrm{mOsm} / \mathrm{L})$} \\
\cline { 2 - 5 } & 0 & 50 & 100 & 150 & 200 \\
\hline Média & $20,60^{\mathrm{e}}$ & $30^{\mathrm{c}}$ & $34,80^{\mathrm{a}}$ & $33,25^{\mathrm{b}}$ & $25,45^{\mathrm{d}}$ \\
Desvio padrão & 1,93 & 3,49 & 3,6 & 3,62 & 2,64 \\
\hline a,b,c,c,e Letras minúsculas diferentes na mesma linha, diferem entre si (P< 0,05$)$
\end{tabular}

Tabela 2. Coeficientes de correlação de Pearson (r) entre soluções hiposmóticas de diferentes osmolaridades e as características seminais avaliadas no sêmen fresco de caprinos $(\mathrm{n}=24$ ejaculados $)$

\begin{tabular}{lccccc}
\hline & \multicolumn{5}{c}{ Osmolaridade das soluções (mOsm/L) } \\
\hline Características seminais & 0 & 50 & 100 & 150 & 200 \\
\hline Motilidade individual & 0,18 & 0,34 & 0,27 & 0,18 & 0,21 \\
Motilidade massal & $-0,24$ & $-0,32$ & $-0,38$ & $-0,31$ & $-0,18$ \\
Viabilidade espermática & $-0,09$ & $-0,03$ & $-0,14$ & $-0,16$ & $-0,08$ \\
Morfologia normal & $-0,20$ & $-0,11$ & $-0,14$ & $-0,06$ & $-0,10$ \\
Integridade acrossomal & 0,14 & $-0,25$ & $-0,13$ & $-0,20$ & $-0,21$
\end{tabular}

* Não foram verificadas correlações significativas entre os parâmetros avaliados $(\mathrm{P}>0,05)$. 


\section{DISCUSSÃO}

Quando o teste hiposmótico foi descrito pela primeira vez para a avaliação do sêmen de humanos, JEYENDRAN et al. (1984) testaram soluções com osmolaridades que variaram de 50 a $300 \mathrm{mOsm} / \mathrm{L}$, obtendo os melhores índices de reação espermática no uso da solução a $150 \mathrm{mOsm} / \mathrm{L}$. Os mesmos autores também testaram diferentes solutos (citrato de sódio, sucrose, melitose, frutose e cloreto de sódio) e associações entre eles e verificaram que os melhores resultados foram obtidos com a utilização da associação entre citrato de sódio $(50 \%)$ e frutose (50\%). No presente trabalho, verificou-se a superioridade $(\mathrm{P}<0,05)$ da solução à base de citrato de sódio e frutose a $100 \mathrm{mOsm} / \mathrm{L}$ em detectar espermatozoides caprinos reativos ao teste hiposmótico, quando comparada às demais soluções testadas. De maneira similar, MARTINS et al. (2006) obtiveram valores de $33,35 \%$ de espermatozoides caprinos reativos ao teste quando utilizada a solução de $100 \mathrm{mOsm} / \mathrm{L}$. FONSECA et al. (2005) também testaram soluções de citrato de sódio e frutose com osmolaridade variando entre 50 a $300 \mathrm{mOsm} / \mathrm{L}$, e observaram que a maior percentagem $(51,5 \%)$ de espermatozoides reativos ao teste foi encontrada em solução a $125 \mathrm{mOsm} / \mathrm{L}$, a qual não foi utilizada no presente estudo, mas cuja osmolaridade aproxima-se da solução de 100 $\mathrm{mOsm} / \mathrm{L}$.

De modo geral, verificou-se uma baixa resposta do sêmen caprino ao teste hiposmótico, haja vista que mesmo os maiores valores encontrados ficaram em torno de $33,35 \%$ de espermatozoides reativos. Esses resultados são inferiores aos encontrados por SALGUEIRO et al. (2003), que obtiveram médias superiores a $50 \%$ de espermatozoides reativos, na mesma espécie. Como o presente trabalho foi realizado na zona rural da cidade de Mossoró, RN, que é uma região conhecida por apresentar extremos de temperatura diária em torno dos $35-39^{\circ} \mathrm{C}$, é possível que os baixos valores estejam associados à influência das altas temperaturas do ambiente sobre a qualidade seminal, alterando o processo de maturação epididimária, comprometendo as estruturas da membrana plasmática dos espermatozóides (HUANG et al., 2000), desse modo, afetando a resposta dos espermatozoides ao teste hiposmótico.

Verificou-se, neste trabalho, que os menores valores $(20,6 \%)$ de espermatozoides reativos ao teste foram obtidos no uso da água destilada como solução hiposmótica a $0 \mathrm{mOsm} / \mathrm{L}$. Diferentemente, estudos com o sêmen de equinos constataram os resultados mais altos de espermatozoides reagidos quando água destilada foi utilizada como solução hiposmótica em comparação a outros solutos (DELL'AQUA et al., 2002; MELO et al., 2003). A água destilada foi superior a outras soluções na avaliação da integridade funcional da membrana em espermatozoides não só de equinos, mas também de cães (QUINTELA et al., 2010). Entretanto, diferenças na composição da membrana plasmática poderiam conferir ao espermatozoide caprino uma resposta inferior a esse meio, quando comparado a outras espécies.

No presente trabalho, não foram encontradas correlações entre os espermatozoides reativos ao teste hiposmótico e as demais características seminais dos caprinos. De modo similar, SANTOS et al. (2006) também não encontraram correlação entre a motilidade espermática e os valores do HOST em sêmen fresco da mesma espécie. Além disso, ENGLAND \& PLUMMER (1993) demonstraram não existir correlação entre a porcentagem de espermatozoides reativos ao teste hiposmótico e outros parâmetros seminais em cães, o que corrobora os dados do presente estudo.

Por outro lado, NUR et al. (2005) demostraram existir uma correlação positiva, moderada e altamente significativa $(\mathrm{r}=52,3 \%$; $\mathrm{P}<$ $0,001)$ entre os resultados do teste hiposmótico e a motilidade espermática em caprinos. Tal correlação tem sido também descrita em estudos com sêmen de bovinos (SIQUEIRA et al., 2007). Além disso, elevadas correlações positivas entre a motilidade e o HOST foram encontradas em sêmen fresco de equino (MELO \& HENRY, 1999), cão (KUMIDIAKA, 1993; RODRÍGUEZ-GIL et al., 1994; BUENO et al., 2001), búfalo e touro (CORREA \& ZAVOS, 1994; LODHI et al., 2008; ZÚCCARI et al., 2009). Ainda, a resposta ao HOST tem sido também positivamente correlacionada tanto com a motilidade quanto com a viabilidade e morfologia normal de espermatozoides de humanos (JEYENDRAN et al., 1984), equinos (MANTOVANI et al., 2002; MELO et al., 2005), búfalos e touros (LODHI et al., 2008).

A existência de correlações entre o teste hiposmótico e a avaliação das demais características seminais é, de fato, controversa, em diferentes espécies. Coeficientes de correlação tão baixos quanto os descritos no presente estudo foram também encontrados por outros autores para o sêmen de caprinos (MARTINS et al., 2006), de equinos (NEILD et al.,1999; SNOECK et al., 2007) e de cães (INAMASSU et al.,1999). Esse fato tem sido explicado pelos autores como sendo devido à especificidade do HOST, pois o edema das células espermáticas é indicativo da integridade da função das membranas espermáticas, enquanto a motilidade depende não somente do transporte de substâncias 
que atravessam as membranas, mas também de um grande número de outras funções bioquímicas, como o metabolismo espermático e a ação microtubular das fibras da região da cauda dos espermatozóides.

Independente de haver ou não a correlação com as demais características seminais, salienta-se que o teste hiposmótico oferece importantes informações acerca da integridade da membrana plasmática das células espermáticas (JEYENDRAN et al., 1984). O uso de diferentes testes específicos que avaliam importantes aspectos estruturais ou funcionais da célula espermática permite aprimorar a seleção de reprodutores e de meios e protocolos de conservação seminal. Desse modo, os resultados de tais testes devem ser somados e encarados como testes complementares e não como excludentes.

\section{CONCLUSÕES}

Embora não tenham sido determinadas correlações entre os resultados do teste hiposmótico e as demais avaliações de sêmen em caprinos, recomenda-se que tal teste seja realizado utilizandose uma solução a base de citrato de sódio e frutose apresentando $100 \mathrm{mOsm} / \mathrm{L}$ para a avaliação da integridade funcional da membrana espermática nesta espécie.

\section{AGRADECIMENTOS}

Os autores agradecem aos proprietários da Fazenda Frei Damião, Mossoró, RN, pela inestimável contribuição ao permitir a realização dos experimentos a campo. Agradecem também ao Banco do Nordeste (BNB) pelo financiamento do projeto. Alguns dos autores receberam bolsa de estudo do Conselho Nacional de Desenvolvimento Científico - CNPq.

\section{REFERÊNCIAS}

BUENO, R.; COSTA, E. P.; GUIMARÃES, J. D.; VALENTIM, F. M. Qualidade espermática de sêmen canino criopreservado. II. Utilização de dois protocolos de resfriamento. Arquivo Brasileiro de Medicina Veterinária e Zootecnia, v. 53, p. 372-379, 2001.

CBRA - COLÉGIO BRASILEIRO DE REPRODUÇÃO ANIMAL. Manual para exame andrológico e avaliação de sêmen animal. 2. ed. Belo Horizonte, CBRA, 1998. www.cbra.org.br, acesso em abril de 2013.

CORREA, J. R.; ZAVOS, P. M. The hypoosmotic swelling test: its employment as an assay to evaluate the functional integrity of the frozen-thawed bovine sperm membrane. Theriogenology, v. 42, p. 351-360, 1994.

DELL'AQUA JR., J.A.; PAPA, F.O.; ZAHN, F.S;
ALVARENGA, M.A.; LEONARDO, H. Novo teste osmótico de avaliação da integridade da membrana plasmática de sêmen congelado equino. Revista Brasileira de Reprodução Animal, v.26, p. 189-191, 2002.

DERIVAUX, J. Reprodução dos animais domésticos. Zaragoza: Editora Acribia, 1980.

ENGLAND, G. C.; PLUMMER, J. M. Hypo-osmotic swelling of dog spermatozoa. Journal of Reproduction and Fertility Supplement, v. 47, p. 261-270, 1993.

FONSECA, J. F.; TORRES, C. A. A.; MAFFILI, V. V; BORGES, A. M.; SANTOS, A. D. F.; RODRIGUES, M. T.; OLIVEIRA, R. F. M. The hypoosmotic swelling test in fresh goat spermatozoa. Animal Reproduction, v. 2, p. 139-144, 2005.

HUANG, S. Y.; KUO, Y. H.; LEE, Y. P.; TSOU, H. L.; LIN, E. C.; LEE, W. C. Association of heat shock protein 70 with semen quality in boars. Animal Reprodution Science, v. 63, p. 231-240, 2000.

INAMASSU, A.; VECHI, E.; LOPES, M. D. Viabilização do teste hipo-osmótico em cães e sua relação com outras variáveis espermáticas. Revista Brasileira de Reprodução Animal, v. 23, p. 302-304, 1999.

JEYENDRAN, R. S.; VAN DER VEN, H. H.; PEREZPELAEZ, M.; CRABO, B. G.; ZANEVELD, L. J. Development of an assay to assess the functional integrity of the human sperm membrane and its relationship to other semen characteristics. Journal Reproduction Fertility, v. 70, p. 219-228, 1984.

KUMI-DIAKA, J. Subjecting canine semen to the hypoosmotic test. Theriogenology, v. 39, p. 1279-1289, 1993.

LEBOUEF, B.; LE VERN, Y.; FURSTOSS, V.; KERBOEUF, D.; GUILLOUET, P.; MAGISTRINI, M. Response of goat sperm to hypoosmotic steps modeled probit analysis. Animal Reproduction Science, v. 36, p. 265-274, 2006.

LODHI, L.A.; ZUBAIR, M.; QURESHI, Z. I.; AHMAD, I.; JAMIL, H. Correlation between hypo-osmotic swelling test and various conventional semen evaluation parameters in fresh nili-ravi buffalo and sahiwal cow bull semen. Pakistan Veterinary Journal, v. 28, p. 186-188, 2008.

MANTOVANI, R.; ROTA, A.; FALOMO, M. E.; BAILONI, L.; VINCENTI, L. Comparison between glycerol and ethylene glycol for the cryopreservation of equine spermatozoa: semen quality assessment with standard analyses and with the hypoosmotic swelling test. Reproduction Nutrition Development, v. 42, p. 217 226, 2002.

MARTINS, L. F.; PEREIRA, M. C. B.; GUIMARÃES, J. D.; COSTA, E. P.; SILVEIRA, T. S.; TORRES, C. A. A.; RODRIGUES, M. T.; BRAZ, V. B. Avaliação espermática e da concentração de proteínas solúveis no plasma seminal de bodes da raça Alpina em regime de monta controlada. Revista Brasileira de Zootecnia, 
v. 35, p. 1653-1659, 2006.

MELO, M. I. V.; HENRY, M. Teste hiposmótico na avaliação de sêmen equino. Arquivo Brasileiro de Medicina Veterinária e Zootecnia, v. 51, p. 71-78, 1999.

MELO, M. I. V.; HENRY, M.; BEKER, A. R. C. L. Teste hiposmótico para avaliação da viabilidade do sêmen eqüino resfriado com diferentes diluidores. Arquivo Brasileiro de Medicina Veterinária e Zootecnia, v. 57, p. 757-763, 2005.

MELO, M. I. V; SNOECK, P. P. N.; BISPO, C.; HENRY, M. Efeito da solução e do tempo de incubação sobre os resultados do teste hiposmótico para o sêmen equino congelado. Revista Brasileira de Reprodução Animal, v. 27, p. 379-380, 2003.

NEILD, D.; CHAVES, G.; FLORES, M.; MORA, N.; BECONI, M.; AGUERO, A. Hypoosmotic test in equine spermatozoa. Theriogenology, v. 51, p. 721-727, 1999.

NUR, Z.; DOGAN, I.; GUNAY, U.; SOYLO, M. K. Relationships between sperm membrane integrity and other semen quality characteristics of the semen of saanen goat bucks. Bulletin of the Veterinary Institute in Pulawy, v. 49, p. 183-187, 2005.

QUINTELA, A.T.; OLIVEIRA, I.R.S.; SOUZA, A.O.; GUSMÃO, A.L.; SILVA, A.R. Water-induced hypoosmotic test for the evaluation of canine sperm membrane integrity. Animal Reproduction, v. 7, p. 70-74, 2010.

REVELL, S. G.; MRODE, R. A. An osmotic resistance test for bovine semen. Animal Reproduction Science, v.36, p. 77-86, 1994.

RODRÍGUEZ-GIL, J. E.; MONSERRAT, A.; RIGAU, T. Effects of hypoosmotic incubation on acrosome and tail structure on canine spermatozoa. Theriogenology, v.42, p. 815-829, 1994.

SALGUEIRO, C. C. M.; NUNES, J. F.; MATEOS-REX, E.; CORDEIRO, M. A.; MAGALHÃES, D. M.; CAVALCANTE, J. M. M; PALÁCIO, A. R. S. Avaliação da qualidade do sêmen caprino pós-descongelamento através do teste hiposmótico. Revista Brasileira de Reprodução Animal, v. 27, p. 377-378, 2003.

SANTOS, A. D. F.; TORRES, C. A. A.; FONSECA, J. F.; BORGES, A. M.; GUIMARÃES, J. D.; COSTA, E. P.; ROVAY, H. Uso de testes complementares para avaliação do congelamento do sêmen de bodes submetidos ao manejo de fotoperíodo artificial. Revista Brasileira de Zootecnia, v. 35, p. 1934-1942, 2006.

SIQUEIRA, J. B.; GUIMARÃES, J. D.; COSTA, E. P.; HENRY, M.; TORRES, C. A. A.; SILVA, M. V. G. B.; SILVEIRA, T. S. Relação da taxa de gestação com sêmen bovino congelado e testes de avaliação espermática in vitro. Revista Brasileira de Zootecnia, v.36, p. 387-395, 2007.

SNOECK, P. P. N.; HENRY, M.; MELO, M. I. V. Efeito de diferentes diluidores sobre a viabilidade espermática pós-descongelação em equinos. Arquivo Brasileiro de Medicina Veterinária e Zootecnia, v. 59, p. 56-64, 2007.

ZÚCCARI, C. E. S. N.; LEITE, P. A.; PASSOS, T. S.; CARRIJO, P. R.; KIEFER, C. Correlação entre métodos de avaliação da integridade da membrana plasmática do espermatozóide bovino criopreservado. Revista Brasileira de Saúde e Produção Animal, v.10, p.678684, 2009. 